\title{
Research on Case Teaching Method and Its Application in Educational Administration Course
}

\author{
Chengyan Cheng ${ }^{1, a}$, Yan Jiang ${ }^{1, b}$ \\ ${ }^{1}$ Nanchang Institute of Science \& Technology, Nanchang, Jiangxi, China, 330008 \\ aemail, ${ }^{\mathrm{b}}$ email
}

Keywords: Case Teaching Method, Application, Educational Administration Course

\begin{abstract}
Case teaching is a critical reflection aims to develop awareness and ability and to promote learners fully understand the importance of teaching in the form of complexity, variability, diversity and other attributes of education management. Unique of education management knowledge, the advantages of case teaching in theory and practice as well as the integration and the case teaching community cooperation and enhance learners' understanding of the complexity of management functions, determines the educational management courses must implement case teaching.
\end{abstract}

\section{Introduction}

In China Normal University, Education Management courses mainly single teacher taught the form. This traditional form of instruction, although easy to impart knowledge management systems and learning, but also causes such as the theory and practice of touch ,, learner is not strong sense of participation, not enthusiastic about learning of a series of well-known problems. In order to improve the education management courses targeted and effective, those in business administration sector and law experts have been widely recognized obvious effect of case teaching, tentatively applied to the teaching of educational management, it is important.

As an effective teaching method, case teaching in recent years, the practice of teaching in educational management application is very wide, both the broad masses of education practitioners recognized and respected, but also by learners love and praise. So, case teaching what distinctive characteristics? Practice mode which it has in educational management practice? Application of these models should pay attention to what issues? This is a logical starting point for many education management discipline workers have to figure out the problem, but also paper.

\section{The Connotation and Characteristics of Case Teaching}

What case teaching? Teaching in Educational Administration teachers and researchers about which there is a different understanding and interpretation. Some people think that is the case teaching case teaching refers to teaching educators in the teaching process to facilitate the learners to understand and grasp the main points of theoretical knowledge taught, relying on the case prepared and carried out. In case the value of case teaching, perfectly positioned and directed to explain or confirm theoretical principles. Educators teaching content in accordance with the teaching plan, a representative selection of typical example, through analysis, to explain the case, the course content will converge in one case described in the event that case integration with the basic theoretical principles inherent to the entire course stand up. Some people think that is a pure case teaching method and lecture method is no substantial difference in the fundamental beliefs and look on the assumption method. Case teaching is a method of classroom teaching reform under the conditions of the traditional teaching ideas, concepts and forms of organization classroom without the slightest change can be easily implemented. Case Teaching and teaching method not only does not conflict with the opposition, on the contrary, they can go hand in hand, the use of cleverly, can complement each other.

I believe that the case refers to educators teaching the theory and practice in line with the organic integration of purpose, to follow the requirements of the purpose of teaching, as the basic material 
to the case, the learner is introduced real-life situation of a particular event by teachers and students, between life and life two-way and multi-directional interaction, the active participation, equality, dialogue and discussion, which focused on the development of critical reflection and awareness groups learners ability to cooperate and to promote learners fully understand the properties of the complex nature of educational management, change, diversity and other important Teaching form.

\section{The Features of Case Teaching}

Case teaching is a teacher in accordance with the purpose and requirements of the teaching activities in classroom teaching, focusing on the course content selected real typical case, by guiding students case analysis, discussions and exchanges, deepen students' course of study basic concepts and principles of understanding so as to enhance students analyze and solve problems ability of a teaching method. It is to improve the quality of classroom teaching, effective way to students' creative thinking and practical ability. Its characteristics are summarized in the following aspects.

Case teaching is teachers teaching the case as the carrier, by setting a series of problem situation, to guide students to discuss and exchange with each other, using the theoretical knowledge learned in solving educational problems arising in practice, improve their judgment, decision making, analyze and solve problems Ability. Teachers can by at the right time in the right way, for the right people, ask the right questions\% to mobilize the enthusiasm of all students

Students are the main classroom activities and the center is always the teachers should be concerned about. Both in the case of selection, set the context, the question presented, the way discussions, content analysis, reaching conclusions, etc., should be given full rights of participation of students, selection and decision-making.

In the case teaching, case selection can be described as the most important and high-quality instant case is the case of the implementation of effective teaching fundamental and protection. Case Teaching as a new teaching methods, the most prominent feature is the truth, situational, sexual, pay attention to practice generated through intuitive, vivid attractive case to stimulate student interest in learning, reflective consciousness and the spirit of exploration.

\section{The Necessity of Case Teaching in Education Management Curriculum}

The unique nature of education management knowledge determines the importance of Case Teaching in Educational Administration in. Education is a financial management knowledge, reality, understanding and critical, highly integrated knowledge, this knowledge with educational organizations manage critical theory paradigm words, but by the experience of diagnosis and interpretation three Dimensions of a whole critique posed. The Educational Organization Phenomenological Paradigm management representative Greenfield is more direct, more clearly stressed that education and natural science knowledge management knowledge very different, and it's personal experience, experience, opportunity and experience directly related, it is more complicated, but also less structured. Known management expert Barnard believes that the organization and management of knowledge there are three different types complement each other, namely: Universal knowledge about specific behavior under certain circumstances, knowledge about certain aspects of the organization of the practice, and specific relevant organizations beyond knowledge. Barnard stressed that, in addition to general common knowledge can be taught and learning, behavior and specific knowledge of the particular organizations rely more on intuition, experience and observation.

The case teaching for the integration of theory and practice provides a unique path. The relationship between education management theory and practice of education management between education teaching and research management has long been a problem Ju Song. For a long time I will not feel that education management theory too empty, from the reality of education management, education management theory that is too superficial, lack of education management practices guiding value. Theory and practice are always placed in an artificial situation of 
confrontation and conflict. However, the case teaching but let us see the hope out of this dilemma. Case teaching is not to discuss the relationship between theory and practice by Jan Peter suppression of this thinking, but not to replace the use of case teaching this critical issue, but both the theory and practice of a particular place among the teaching situation, while giving seminars and dialectical use.

Third, the case teaching can effectively develop learners' awareness and ability of community cooperation. Generally, people have the ability to express their ideas and their defense, the ability to advise others, the ability to listen carefully to and cooperation with the people around them and build a new idea, and many other capabilities are available through the organization of effective teaching case and developed. And a study in cooperation with each other, support groups generated effects are far superior to individual personal learning has an effect. In the context of the case management and brainstorming, the various views and interpretations will be diverse up and enriched. In the case of teaching this learning environment, learners not only learn to be responsible and strive to become a true learners and active participants, and will learn to collaborate with others, and strive to contribute to the learning of others. In short, an important purpose and function of case teaching is that nurtured through case teaching, learners learn to share both happy, learn to share more responsibility.

Fourth, the case teaching can make learners feel managers' contradictory situation, the complexity of the educational experience of management, to prevent making simplistic and one-sided interpretations of the education management behavior. Unlike the case teaching method to teach a notable feature is that it is closer to the maximum distance teaching situations and practical management situations. In the case of teaching, learners discuss the problem actually is the management situation in the real management problems occur, these management challenges in addition to spatial and temporal variations, its authenticity is totally guaranteed. In this seminar is learner management problems in the process, come to realize how complex management, realized that the charm and essence of management. I believe that in education management, managers can manage complex concept of setting up the vital, it relates to the effectiveness of management. Unfortunately, in the years of management education teaching process, I found that many learners lack of such a complex concept, management or be seen as a simple enough skills and techniques, either as a set of externally granted control force. So management is simplified, one-sided, trickery and tyranny of the.

\section{The Pattern Classification and Its Applicability of Case Teaching in Education Management}

Experience Type of Case Teaching. A case is often a description of the actual situation. Teaching teachers often use their own practical experience to solve the various problems encountered in the classroom, and in the case presented in the form of classroom teaching. This type of case teaching experience not only provides real examples and scenarios to provide reference for other educators, and education and training is an effective way of teaching personal reflection. With this experiential teaching, education for teacher attention to detail, focusing on the development of education around the situation in a timely manner to reflect and explore the hot issues of education has an important application value and incentive.

Academic Case Teaching. Academic research case teaching applies to "how" and "why" question type and object of study is usually an event currently taking place. This teaching model is usually written by professional researchers in the field of education, mainly to explain the occurrence in real life events complex cases. This type of model can fully reflect the difference between academic teaching and other teaching methods Case lies. Educational Administration set management and property subject to a dual education, and scientific value, professionalism and complexity, and other characteristics.

\section{The Problems that Need Attention of Case Teaching in Educational Management}

Case teaching is widely used in educational management practice by researchers and teachers and 
students of all ages. In order to further promote the case teaching more rigorous, standardized development path, we believe that the use of case teaching in educational management practices

Careful Preparation. When the Educational Administration classroom teachers prepare before class, case selection is the most important part. First, teachers should understand the students 'learning ability and cognitive level and choose to accept students' learning needs and related cases. Secondly, the notion of a story to be expressed, principles and ideas of the students can understand and grasp, capable of initiating students to think through the case, and enhance classroom interaction, under the guidance of teachers, to provide students with a broader ideas and space.

For Weaknesses, Strengthen Teacher's Training. In response to case writing, case studies, case evaluation of the proposed new requirements, it is necessary for different weaknesses, strengthen teachers' knowledge and skills training to enable them to update the concepts of education, quickly grasp and flexibility in the use of the case teaching needed in skill.

Case Teaching although belonging to empirical research in the study of nature, but did not experiment, calculation basis to provide accurate figures and indicators, teachers have to rely on judgment and interpretation, which cannot be avoided with a strong subjective will. Teachers will not help according to their academic background, teaching experience and a different view of things to come to a final conclusion. In the teaching process, in order to avoid cases of students catch focus, analyze problems ideas are wide of the mark, the teacher must explain before the case related to the present case the main theoretical knowledge points succinctly explain clearly, and then guide the students how to use. Deal correctly with new dynamic relationship between good case teaching process applications teachers and students, teachers should be able to accept different views and their own, different perspectives of students, teachers should allow students to views presented opposing views, and always will study and train students thinking as a classroom task priority.

\section{Conclusion}

In the case teaching process teachers should carefully observe, monitor and judge student responses are consistent with design aspects of their teaching, so that appropriate adjustments and perfect after school, it will promote the case teaching process continue to a higher level. School reflection is not only to promote the improvement of classroom teaching process it is also the process of promoting the growth of teachers and reflection. By summing up the experience and lessons they can provide guidance and teaching reference for future re-designed.

\section{References}

[1] Jia Xinzhang, Li Jingyuan. Nanjing Institute of Technology, Vol. 6 (2014) No 53, p.25-26

[2] Peng Sue, Wang Yunhui, Wang Qunyong. Economic Review, Vol. 12 (2015) No 27, p.74-76

[3] Qian Xiyuan, Jing Jianfen. Degrees and Graduate Education, Vol. 30 (2014) No 19, p.144-145

[4] Wang Kuailiang. Secondary Education, Vol. 29 (2008) No 27, p.21-23

[5] Zhang Gongxu, Sun Jing. Science and Technology Innovation, Vol. 8 (2013) No 27, p.57-60 